\section{The In Situ Effect of Titanium Tetrafluoride Gel on Erosion/Abrasion Progression in Human Dentin}

\author{
Taís Fonseca Mantilla1, Cecilia Pedroso Turssi², Thayanne Monteiro Ramos- \\ Oliveira ${ }^{1}$, Camila Vieira da Silva ${ }^{1}$, Luis Cláudio Suzuki³ ${ }^{3}$ Patricia Moreira de \\ Freitas ${ }^{1}$
}

'Dental School, USP - Universidade de São Paulo, São Paulo, SP, Brazil ${ }^{2}$ Institute and Dental Research Centre, Faculdade São Leopoldo Mandic, Campinas, SP, Brazil 3IPEN, USP - Universidade de São Paulo, São Paulo, SP, Brazil

Correspondence: Patricia Moreira de Freitas, Av. Professor Lineu Prestes, 2227 - Cidade Universitária, Butantã, São Paulo, Brasil. Tel: +55-11-30917645. e-mail: pfreitas@usp.br
Erosion incidence is increasing and its control is still a challenge in clinical practice. This study evaluated $4 \% \mathrm{TiF}_{4}$-gel effects on eroded human dentin subjected to in situ erosive/ abrasive episodes. Seventy-two previously eroded dentin slabs ( $0.05 \mathrm{M}$ citric acid, $\mathrm{pH} 2.3$, $20 \mathrm{~min})$ were allocated to 6 groups $(n=12)$ according to the treatment to be performed during the in situ phase and number of erosive/abrasive cycles, as follows: $4 \% \mathrm{TiF}_{4}$-gel applied once $\left(\mathrm{TiF}_{4} 1\right)$, twice $\left(\mathrm{TiF}_{4} 2\right)$ or three times $\left(\mathrm{TiF}_{4} 3\right)$ followed by 1,2 and 3 erosive/ abrasive cycles, respectively. Gel was applied before the beginning of the next cycle. Control groups were subjected to 1 (C1), 2 (C2) and 3 (C3) erosive/abrasive cycles only. A seventh group $(n=12)$ comprised in vitro uneroded samples (UN) subjected to 3 erosive/ abrasive cycles. Each cycle corresponded to 2 days of erosive (citric acid 0.5\%, pH 2.6, $6 \mathrm{x} /$ day) and abrasive (electric toothbrush, $10 \mathrm{~s} / \mathrm{sample}, 1 \mathrm{x} /$ day) challenges. Samples were evaluated under profilometry and environmental scanning electron microscopy (ESEM). Atomic force microscopy images (AFM) were also made $(n=3)$. Repeated measures 2-way ANOVA and Tukey test $(p<0.001)$ showed that $\mathrm{TiF}_{4} 2$, which did not differ from $\mathrm{TiF}_{4} 1$ and $\mathrm{TiF}_{4} 3$, revealed a significant reduction in surface loss compared to all control groups. $\mathrm{TiF}_{4} 1$ and $\mathrm{TiF}_{4} 3$ showed no significant difference from $\mathrm{C} 1$, but both groups demonstrated significantly smaller surface loss than C2 and C3. ESEM and AFM micrographs suggested alterations on treated surfaces compared to samples from control groups, showing reduced diameters of dentinal tubules lumens. Therefore, $\mathrm{TiF}_{4}$ was able to reduce the progression of erosive/abrasive lesions.
Key Words: $\mathrm{TiF}_{4}$, fluoride, tooth wear, scanning electron microscopy, atomic force microscopy.

\section{Introduction}

Dental erosion is a chemical process, characterized by chronic and pathological dissolution of dental hard tissues due to exposure to a variety of non-bacterial acids (1). Preventive and control measures to interrupt the progression of the erosive lesion have been proposed and include the strategy of increasing the acid resistance of dental hard tissues, which is the potential role of fluoride products.

In fact, fluoride products commonly used for caries prevention, as sodium fluoride, amine fluoride and acidulated phosphate fluoride, have proven to be partially effective in controlling erosive lesions $(2,3)$, as they promote the precipitation of minerals like calcium fluoride $\left(\mathrm{CaF}_{2}\right)$ on the eroded surface (4). They form a layer that acts as a physical barrier to the action of acids, apart from acting as a mineral reservoir, which under erosive challenge is able to release calcium and fluoride (5).

Currently, fluoride compounds of polyvalent metal ions, especially titanium tetrafluoride $\left(\mathrm{TiF}_{4}\right)$, have been studied due to their unique interaction with the tooth structure, leading to the formation of an acid-resistant glaze-like layer capable of adhering strongly to the tooth surface (6). Among the existing theories to explain its action, one is that titanium is capable of reacting with the oxygen atoms of the phosphate groups of the dental tissue, forming stable titanium oxides (7) or organometallic complexes that can act as a diffusion barrier (8).

In order to determine the most effective treatment for erosion control, there is need for more precise indication of the available fluoride products. $\mathrm{TiF}_{4}$ has a peculiar mechanism of action and a significant potential in reducing erosion progression (3), however, there is still no consensus on the ideal formulation for this fluoride's clinical use $(2,9)$.

The present study investigated the possible anti-erosive effects produced by $4 \% \mathrm{TiF}_{4}$ gel, under in situ conditions, with a simulated high incidence of erosive/abrasive episodes. In case of positive results regarding the control of erosion progression, it could give professionals an effective alternative for erosive lesions' in-office treatment.

The hypothesis tested was that dentin treated with $4 \%$ $\mathrm{TiF}_{4}$ gel - applied once, twice or three times - will be more resistant to recurrent erosive challenges than untreated dentin. 


\section{Material and Methods}

\section{Experimental design}

The present two-phase-designed in situ study was conducted with 12 volunteers. The independent variables were "volunteer" and "treatment" at seven levels: three control groups subjected to 1 (C1), 2 (C2) and 3 (C3) erosive/ abrasive cycles solely; an extra control group comprising in vitro uneroded samples (UN) subjected to 3 erosive/abrasive cycles and three experimental groups, in which $4 \% \mathrm{TiF}_{4}$ gel was applied once $\left(\mathrm{TiF}_{4} 1\right)$, twice $\left(\mathrm{TiF}_{4} 2\right)$ or three times $\left(\mathrm{TiF}_{4} 3\right)$ followed by 1, 2 and 3 erosive/abrasive cycles, respectively. The dependent variable was surface loss, measured by profilometry (in $\mu \mathrm{m}$ ). Furthermore, micrographs were obtained in Environmental Scanning Electron Microscope (ESEM) and Atomic Force Microscope (AFM) to observe the surface morphology produced by the tested treatments.

\section{Sample Preparation}

One hundred and thirty samples were obtained from cervical areas of 65 third molar roots, stored in chloramine- $T$ solution $\left(4^{\circ} \mathrm{C}\right)$ for up to three months after extraction by a low-speed water-cooled diamond saw (ISOMET 1000; Buehler Ltd., Lake Bluff, IL, USA). Dentin slabs ( $3 \times 3 \times 1 \mathrm{~mm}$ )

on the dentin surface (visible cracks, enamel remaining, unpolished surfaces). Surface microhardness was tested (Microhardness tester HMV-2000; Shimadzu, Kyoto, Japan) to standardize the hardness of samples selected for the study. Three indentations were made per sample with a Knoop indenter ( $10 \mathrm{~g}$ for $10 \mathrm{~s}, 50 \mu \mathrm{m}$ apart). Eleven samples presented outlier microhardness values and were discarded. After that, the remaining 119 samples were evaluated in optical profilometer (3D PROSCAN 2100; Scantron, Eagan, MN, USA) for determination of surface curvature. From them, the 84 samples with the smallest surface curvature were selected and included in the study (mean surface curvature $=0.27 \pm 0.18 \mu \mathrm{m}$ and mean surface microhardness $=78.62 \pm 8.13$ ).

All selected samples were sterilized with gamma radiation and randomly distributed in 7 groups $(n=12)$. All samples had their surfaces protected by two strips of adhesive tape (UPVC Graphic Tape; Chartpak, Leeds, AL, USA) (1.0 mm width each), leaving a central window $(3 \times 1$ $\mathrm{mm}$ ) exposed and two lateral reference areas $(3 \times 1 \mathrm{~mm}$ on each side).

\section{Erosive-like Lesions Formation}

Before the surface treatment, samples from groups $\mathrm{C}_{1}, \mathrm{C}_{2}, \mathrm{C}_{3}, \mathrm{TiF}_{4} 1, \mathrm{TiF}_{4} 2$ and $\mathrm{TiF}_{4} 3$ were subjected to immersion in a $0.05 \mathrm{M}$ citric acid (pH 2.3) solution (citric acid monohydrate; Sigma-Aldrich Brazil Ltd., São Paulo, SP, Brazil) (10), at room temperature and under constant stirring (20 min, $35 \mathrm{rpm}$ ).

At the end of the in vitro erosion process, surface profilometry was conducted (scan - $2 \mathrm{~mm}$ (X axis) $\times 1$ $\mathrm{mm}(Y$ axis)), in order to confirm the homogeneity of the obtained lesions (mean $=3.92 \pm 0.35 \mu \mathrm{m}$ ). All samples were then examined under ESEM (Hitachi Analytical Microscope TM3000 Table Top; Hitachi, Tokyo, Japan) (1000x and 3000x magnifications), as further described.

\section{Selection of Volunteers}

$G^{*}$ Power 3.1.5 software was used for a prioricalculation of the required sample size. Twelve volunteers were enrolled assuming a significance level of $\alpha=0.05$, a desired power of $\alpha=0.85$ and an anticipated large effect size between groups. This study was conducted in accordance with the principles established in Declaration of Helsinki and approved by the Ethics Committee of the Dental School of Universidade de São Paulo (Protocol no. 544.566). All volunteers (female, 20-35 years) selected to participate of the in situ phase were given informed, written consent. The following criteria for inclusion of the participants were considered: to have all teeth; to be in good oral health; to live in the urban area of São Paulo and present stimulated salivary flow $>0.7 \mathrm{~mL} / \mathrm{min}$. The exclusion criteria were: those who presented any sort of systemic pathology; visible plaque, cavities, gingivitis or periodontal disease; orthodontic devices; gastroesophageal reflux disease; had regular use of tobacco and alcoholic beverages and/or were pregnant or breastfeeding.

\section{Setting of Intraoral Devices}

In both stages was performed permutation of samples in the niches, so that the sample's position would not influence the results, since most of the volunteers were right-handed. Samples were placed bilaterally in mandibular intraoral devices. Devices were made of acrylic resin and contained two niches $(4 \times 4 \times 2 \mathrm{~mm})$ (Fig. 1). Surfaces of samples were set with a recess of $0.5 \mathrm{~mm}$ in relation to the limits of the niches, avoiding abrasion from contact with the mucosa.

To prevent the influence of fluoride in the control samples, groups were separated in two phases as shown in Figure 2. During both phases of the study, samples were randomly placed.

\section{In situ Phase}

Before the beginning of in situ stage and between the Control and Experimental phases of the study, was included a run-in period of 2 days and a wash-out of 5 days. In this period and through the entire in situ phase, 
all volunteers performed their dental hygiene without the in situ devices, with a fluoridated toothpaste (Colgate Maximum Protection Anti-Caries ${ }^{\circledR} 1,500$ ppm F-; ColgatePalmolive, Osasco, SP, Brazil), toothbrush and dental floss provided by the researcher.

Throughout in situ phase, the devices were inserted 2 $\mathrm{h}$ before the first erosive challenge to form the acquired pellicle. Then were performed the erosive challenges, which consisted on 6 ex vivo immersions a day ( 2 min each) with $1.5 \mathrm{~h}$ intervals between them, in $20 \mathrm{~mL}$ of $0.5 \%$ citric acid (pH 2.6) (11). As each cycle corresponded to 2 days of erosive/ abrasive cycling, one cycle comprised 12 acid challenges. After each immersion, the excess acid was poured onto an absorbent paper and the device was reinserted in the mouth. Demineralizing solution was replaced at the beginning of each day and had its $\mathrm{pH}$ monitored. The devices were stored overnight and during meals in moistened gauze with distilled water in the refrigerator. After meals, drinks and oral hygiene, volunteers were instructed to wait $15 \mathrm{~min}$ for reinsertion of the device in the mouth.

Toothbrush abrasion was performed 60 min after the last erosive challenge of each day. Following the protocol proposed by Schlueter et al. (11), volunteers used an electric toothbrush equipped with a pressure sensor, which is activated in $2.5 \mathrm{~N}$ (Oral B Professional Care 3000; Oral B, Schwalbacham Taunus, Germany). The brushing was always started on the occlusal surfaces of the volunteer's own mandibular teeth for $15 \mathrm{~s}$ to produce a toothpaste (Colgate Maximum Protection Anti-Caries ${ }^{\circledR} 1,500$ ppm F-, Colgate-Palmolive)/saliva slurry. After that, brushing was
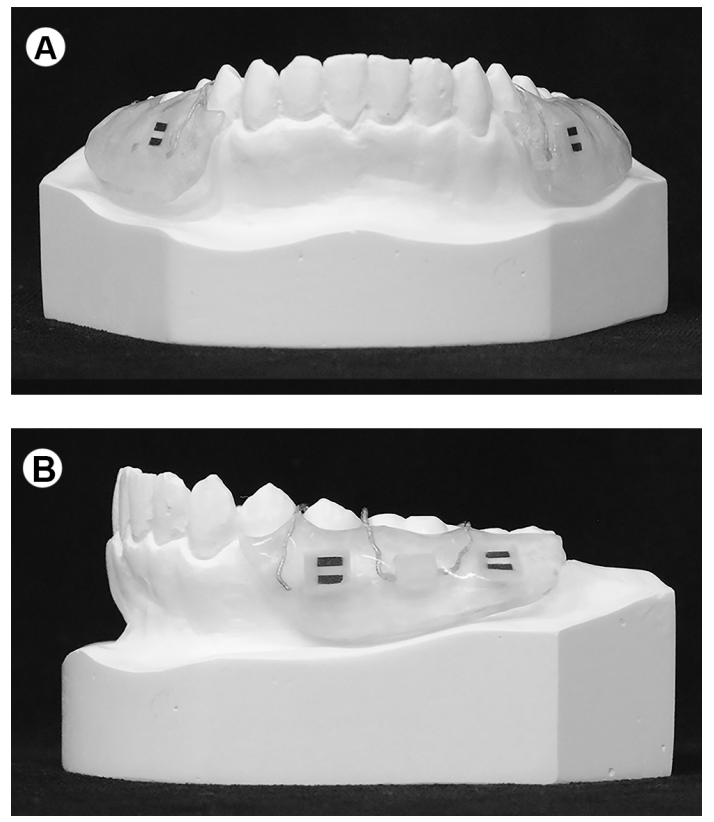

Figure 1. In situ intraoral devices. Front (A) and side (B) views. performed intraorally for $10 \mathrm{~s}$ on each sample, followed by rinsing with running water for $3 \mathrm{~s}$ and removal of the device (11). The device was then rinsed with water for 1 min to remove remnants of toothpaste, reinserted in the mouth and used for another $30 \mathrm{~min}$.

\section{$\mathrm{TiF}_{4}$ Application}

During experimental phase, 4\% $\mathrm{TiF}_{4}$ gel applications were performed on the 1st, 3rd and 5th days of cycling (Table 1). Three samples (two in one side and one in the other) were positioned on each device in this phase. Before each application (3rd and 5th), one sample was removed in order to avoid the possible influence of other applications (presence of fluoride in the mouth) on this one and was not reinserted, because of the possible contamination of samples during analysis. So, on samples of $\mathrm{TiF}_{4} 1$ group, $\mathrm{TiF}_{4}$ was applied once, on $\mathrm{TiF}_{4} 2$ samples, twice and on $\mathrm{TiF}_{4} 3$ samples, three times. As samples were removed, they were kept in relative humidity and stored at $4{ }^{\circ} \mathrm{C}$. In the control phase, in order to allow the comparison between phases, four samples were placed on each device (two in each side) and were removed before the beginning of the next erosive/abrasive cycle.

For the fluoride treatment, samples were dried with absorbent paper and subjected to application of $4 \% \mathrm{TiF}_{4}$ gel $(24,530$ ppmF) (2). Fluoride was manipulated by the researcher addiing $0.4 \mathrm{~g}$ of titanium fluoride (IV) (SigmaAldrich Brazil Ltd.) in $10 \mathrm{~mL}$ of distilled water. Next, $1.0 \mathrm{~g}$ of carboxymethylcellulose (Sigma-Aldrich Brazil Ltd.) $(\mathrm{pH}$ 1.5) was added. In the predetermined times, $20 \mu \mathrm{L}_{\text {of }} \mathrm{TiF}_{4}$

Table 1. Steps followed during the experimental phase

\begin{tabular}{ccc}
\hline Cycle & Day & Steps \\
\hline 1 & 1 & 1st TiF4 application + Erosive/abrasive cycling \\
& 2 & Erosive/abrasive cycling \\
2 & 3 & $\begin{array}{c}\text { TiF4 } 1 \text { sample removal + 2nd TiF4 } \\
\text { application + Erosive/abrasive cycling }\end{array}$ \\
& 4 & Erosive/abrasive cycling \\
3 & 5 & $\begin{array}{c}\text { TiF4 2 sample removal + 3rd TiF4 } \\
\text { application + Erosive/abrasive cycling } \\
\end{array}$ \\
& 6 & Erosive/abrasive cycling \\
\hline
\end{tabular}

\begin{tabular}{|c|c|c|c|c|c|c|}
\hline \multicolumn{7}{|c|}{ Root dentin slabs } \\
\hline \multirow{2}{*}{ UN } & \multicolumn{6}{|c|}{ Erosive-like lesions formation } \\
\hline & $\mathrm{C} 1$ & $\mathrm{C} 2$ & $\mathrm{C} 3$ & $\mathrm{TiF}_{4} 1$ & $\mathrm{TiF}_{4} 2$ & $\mathrm{TIF}_{4} 3$ \\
\hline \multicolumn{4}{|c|}{ situ Control Pl } & \multicolumn{3}{|c|}{ In situ Experimental Phase } \\
\hline
\end{tabular}

Figure 2. Division of the groups during the in situ phases. 
were applied on each sample (active application, $4 \mathrm{~min}$ ). Excess fluoride gel was removed with cotton and the dentin surface dried with absorbent paper.

\section{Profilometric Analysis}

Profilometric analysis was performed in an optical profilometer (3D PROSCAN 2100, Scantron). After removing the tape, the sensor of the equipment was positioned on the left top of each sample and moved $1 \mathrm{~mm}$ down and 0.5 $\mathrm{mm}$ right in order to start the scanning always at the same point. A central area of each sample $[2 \mathrm{~mm}$ (X axis) $\times 1 \mathrm{~mm}$ (Y axis)] - corresponding to the treated area and reference surfaces on both sides- was scanned, thus obtaining the depth of the lesion (3-pt step height). Samples were kept at relative humidity until scanning time in order to prevent dentin dehydration. Immediately before analysis, the excess water was removed with an absorbent paper (12). All samples were analyzed in profilometer three times during the experiment: curvature analysis, standardization of erosive-like lesions formed in vitro and in situ posttreatment evaluation.

\section{Environmental Scanning Electron Microscope (ESEM) Analysis \\ All samples were analyzed under ESEM (Hitachi Analytical Microscope TM3000 Table Top; Hitachi) in two experimental times, before and after in situ phase. Samples were fixed with cyanoacrylate-based adhesive on aluminium stubs and positioned as on profilometry, in order to perform the scanning always in the same area (1000x and $3000 \times$ magnifications).}

\section{Atomic Force Microscope (AFM) Analysis}

Three samples from each experimental group were randomly selected and observed in AFM (Nanosurf AFM Flex; Nanosurf, Liestal, Switzerland). One sample at a time was placed under the mechanical silicon probe with high frequency and resonance to scan in tapping mode. A scan rate of $20 \mu \mathrm{m} / \mathrm{s}$ and a resolution of 256 x 256 pixels were used. For each sample, a three-dimensional image of $20 \mu \mathrm{m} \times 20 \mu \mathrm{m}$ was obtained and allowed the observation of treated surfaces.

\section{Statistical Analysis}

The difference between surface losses measured after the in situ phase and the erosive-likelesion was used as the outcome value for each specimen. Before data analysis, normality of distribution was verified with Shapiro-Wilk tests, which showed that data violated normal distribution. To fit normality, data were root-square transformed and two outliers identified in the Box-Plot were excluded. Transformed data were evaluated using a repeatedmeasures two-way analysis of variance (ANOVA), according to the general linear model, to examine the effects of the independent variables Treatment and Volunteers on surface loss (dependent variable). Post-hoc comparisons were performed using Tukey's test. Significance level was set at 5\% and statistical procedures were carried out using SPSS 20.0 (SPSS Inc., Chicago, IL, USA).

\section{Results}

\section{Profilometry}

In order to ensure the reliability of this study results, the statistical power was calculated (0.72) and considered satisfactory (13). Repeated-measures two-way ANOVA, performed with transformed data, showed that surface loss was significantly affected by the treatments $(p<0.001)$. Tukey test demonstrated that the specimens from the $\mathrm{TiF}_{4} 2$ group (2 cycles), which did not differ from any of the other two $\mathrm{TiF}_{4}$-treated groups, revealed significantly lower surface loss when compared to all the untreated control groups. $\mathrm{TiF}_{4} 1$ and $\mathrm{TiF}_{4} 3$ groups ( 1 and 3 applications, respectively) did not differ from $\mathrm{C} 1$ group, but both $\mathrm{TiF}_{4} 4$-treated groups presented significantly lower surface loss than that noticed for the remaining untreated control groups (C2 and C3). The highest change in surface loss was found in $\mathrm{C} 3$ and in the in vitro uneroded group (UN) (Table 2).

\section{Scanning Electron Microscopy}

Figure 3 shows the pattern of surface morphology presented by the samples of the in vitro uneroded control

Table 2. Mean values (standard deviation) of the original data, in $\mu \mathrm{m}$, of surface loss of human dentin measured after the in vitro erosion, after the surface treatment and in situ erosion, followed by the corresponding difference (Surface loss after in situ stage minus erosive like-lesions)

\begin{tabular}{|c|c|c|c|}
\hline \multirow{2}{*}{ Treatment } & \multicolumn{2}{|c|}{ Surface loss } & \multirow{2}{*}{ Difference } \\
\hline & Erosive-like lesions (in vitro) & After in situ stage & \\
\hline $\mathrm{TiF}_{4} 1$ (1 cycle) & $4.080(0.856)$ & $6.910(0.950)$ & $2.830(1.284) \mathrm{AB}$ \\
\hline $\mathrm{TiF}_{4} 2$ (2 cycles) & $4.662(0.656)$ & $6.480(1.528)$ & $1.818(1.296) \mathrm{A}$ \\
\hline $\mathrm{TiF}_{4} 3$ (3 cycles) & $3.692(0.554)$ & $8.117(6.298)$ & $4.425(6.473) \mathrm{AB}$ \\
\hline C1 (1 cycle) & $3.642(0.484)$ & $10.396(2.283)$ & $6.754(2.477) \mathrm{BC}$ \\
\hline C2 (2 cycles) & $3.638(0.788)$ & $11.998(2.050)$ & 8.359 (1.797) C \\
\hline C3 (3 cycles) & $4.004(0.664)$ & $20.523(7.691)$ & $16.518(7.726) \mathrm{D}$ \\
\hline UN (3 cycles) & ---- & $20.844(9.121)$ & $20.844(9.121) \mathrm{D}$ \\
\hline
\end{tabular}

Means followed by different capital letters differ from each other. 
(UN) group and C3, before and after the in situ phase. Prior to the erosive/abrasive cycling performed during the in situ phase, the UN group (Fig. 3A) had a flat surface with open and homogeneously distributed dentin tubules. Compared with UN, the C3 group, (Fig. 3B - before in situ phase), presented a more irregular surface pattern, with more open dentinal tubules. After the in situ phase and without being subjected to any additional treatment beyond the erosive/abrasive cycling, UN group (Fig. 3 C) showed surface damage caused by erosive/abrasive challenges, although the tubular opening pattern shown before the in situ phase was maintained. However, samples from C3 group (Fig. 3D), which were removed from the oral cavity after the same amount of cycles that UN, showed a change in surface pattern with a lesser amount of exposed tubules.

Comparing the control groups (Figs. 4A, $4 \mathrm{C}$ and $4 \mathrm{E}$ ) and experimental groups (Figs. 4B, 4D and $4 \mathrm{~F}$ ), it appears that the $\mathrm{TiF}_{4}$, regardless of the amount of applications, has caused changes in the characteristics of treated surfaces, promoting an apparent reduction of the diameter of the tubule lumens, which became squashed (diamond shaped).

\section{Atomic Force Microscopy}

The applications of $\mathrm{TiF}_{4}$ (Figs. 5B, 5D and 5F) modified the surface topography of the samples compared to all
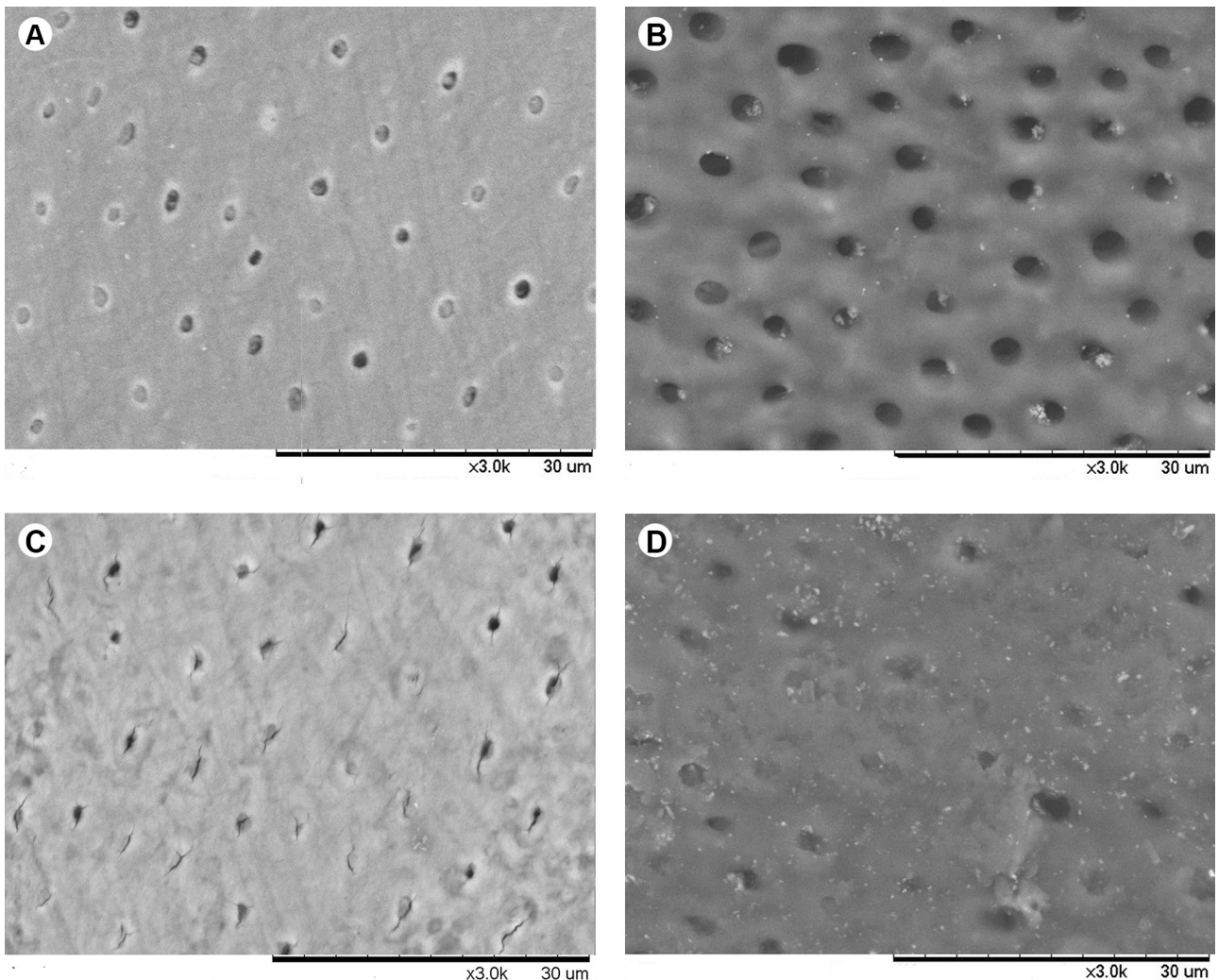

control groups (Figs. 5A, 5C, 5E and 5G) and, despite that tubules remained open, they appeared partially obliterated and in reduced amount. Furthermore, the rough appearance of the samples without treatment was decreased by $\mathrm{TiF}_{4}$.

\section{Discussion}

This study was conducted following an in situ model, approaching at maximum the physicochemical conditions that occur in the oral cavity during the erosion, in which the presence of saliva (14) and acquired pellicle (15) are capable of modifying the formation of erosive lesions.

For assessment of the effects by surface treatments, the optical profilometer was used (16), as it allows the measurement of surface loss without damaging the demineralized organic matrix that may remain after exposure to oral environment. The matrix, even though suggested to be removed prior to laboratorial analysis (17), may have been important to inhibit the progression of erosive lesions, especially when treated with $\mathrm{TiF}_{4}$. Some authors reported that $\mathrm{TiF}_{4}$ produces a glaze on the dentin surface $(6,18)$ and one of the strongest actual theories to explain this formation considers the direct interaction between titanium and the organic matrix (8).

The current study had its hypothesis accepted since the treatment with $4 \% \mathrm{TiF}_{4}$ gel showed positive results in

Figure 3. Electromicrographs of the UN and C3 groups (equivalent amount of cycles) before (A and B, respectively) and after (C and D) respectively) the in situ stage. $3000 \times$ magnification. 
the control of erosive progression compared to untreated dentin. $\mathrm{TiF}_{4}$ treated groups led to lower dentin surface loss compared to controls with equivalent amounts of erosive/ abrasive cycles. These results may indicate formation of a glaze layer on the tooth surface since the first moment of $\mathrm{TiF}_{4}$ application (3). The glaze acts as a diffusion barrier and a reservoir of fluoride ions (5), which may have been responsible for reducing the surface loss of the experimental groups compared to control groups, since it is able to slow down the dissolution of dental tissue facing acid challenges (5). Although it could not be identified on the electromicrographs, probably due to the employed technique, treated surfaces appeared to have different characteristics compared to the untreated ones. After TiF application, samples presented a more regular surface and partially obliterated tubules, which confirms that the $\mathrm{TiF}_{4}$ gel was able to alter the pattern of the eroded surfaces.

These favorable properties of $\mathrm{TiF}_{4}$ are, however, dependent on the concentration, $\mathrm{pH}$ and presentation form used for application $(2,9)$. As there is still no consensus on the ideal formulation, the manipulated product used in this study was determined by the feasibility and probability of its clinical use in the future. It was decided to apply $\mathrm{TiF}_{4}$ gel (2), because it would be an easy form to be used by the dentist and a comfortable presentation for the patient, since it can be rapidly applied and has no unpleasant taste. The native $\mathrm{pH}$ was used because of the efficiency demonstrated in other studies concerning the precipitate formation and
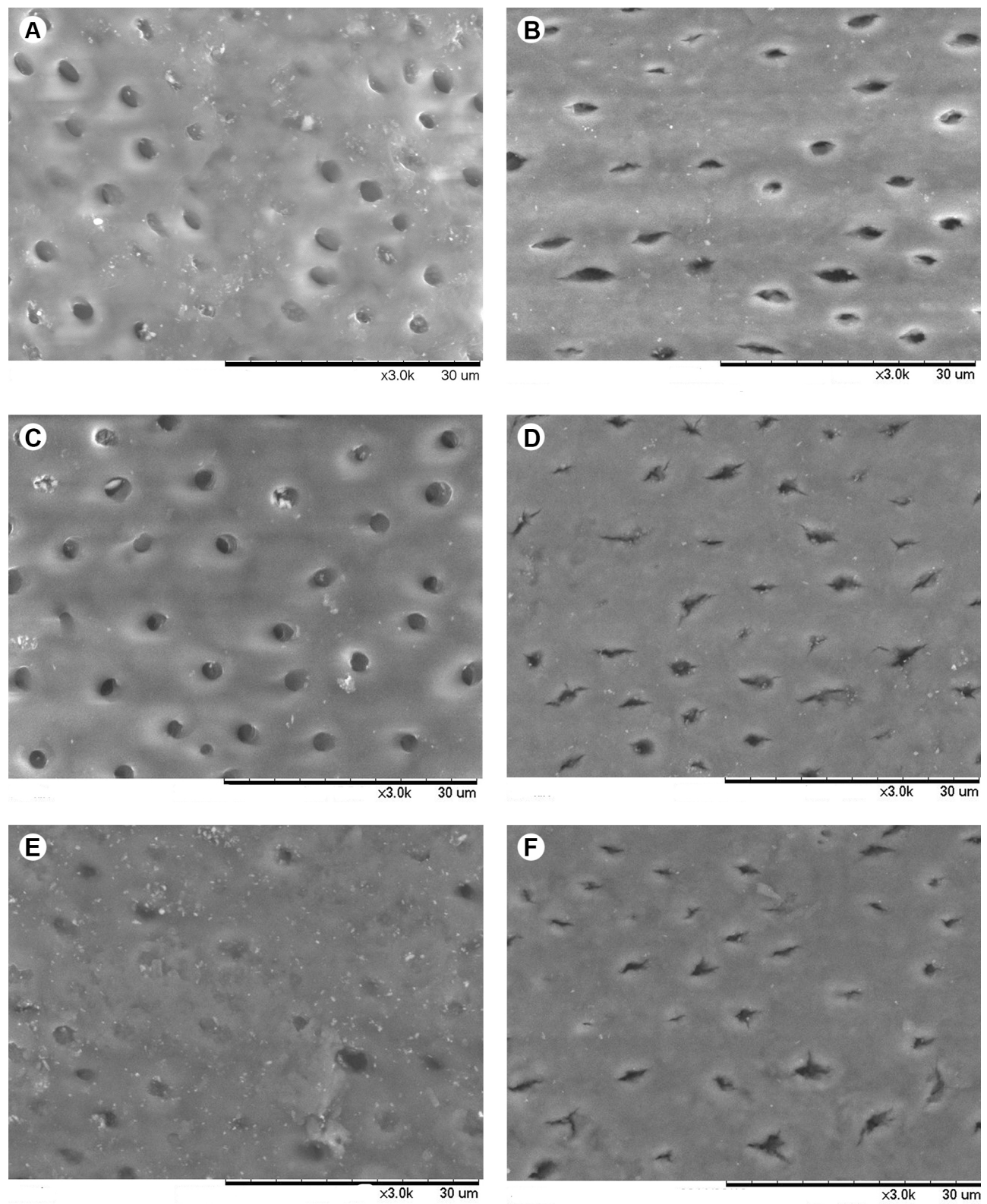

Figure 4. Electromicrographs of $\mathrm{C}_{1}(\mathrm{~A}), \mathrm{TiF}_{4} 1$ (B), $\mathrm{C} 2(\mathrm{C}), \mathrm{TiF}_{4} 2(\mathrm{D}), \mathrm{C} 3(\mathrm{E})$ and $\mathrm{TiF}_{4} 3(\mathrm{~F})$ groups after the in situ stage. 3000× magnification. 
demineralization reduction (9). The concentration of $4 \%$ obtained better results compared to lower concentrations, possibly due to its capability of forming a thicker and tenacious glaze after treatment (18).

On the other hand, with the protocol applied in the present study, even after repeated applications, $\mathrm{TiF}_{4}$ did not show cumulative effects. As its protection is basically produced by glaze formation, once all sites are complexed with $\mathrm{Ti}$ ions, it may not be possible to enhance it. Especially considering that the used gel had a high concentration of $\mathrm{TiF}_{4}$ in its formulation, which may increase the amount of Ti available on the mouth since thefirst application.

Concerning its clinical application perspectives, this lack in dose-response could be positive, since it would not be necessary to reapply the product in a short time, minimizing its possible side effects. In this regard, it should be considered that $\mathrm{TiF}_{4}$ hydrolyzation generates an acidic solution, because of $\mathrm{H}^{+}$ions release, which may lead to a relative cytotoxicity when applied directly onto cells, compared to sodium fluoride application (19). However, its cytotoxicity was not higher than the acidulated phosphate fluoride, which is commercially available (19). Also, when $\mathrm{TiF}_{4}(0.12 \%)$ was administered intragastrically to rats, they did not show signs of systemic toxicity (20). In this sense, if applied topically, it may be considered safe to patients.

Although erosion could be reduced in the present study, treatment application was not able to interrupt completely its progression. Even considering the presence of a dense demineralized organic matrix layer, which provides partial protection against erosive challenges (21), its association with the glaze seems to have been insufficient to inhibit dentin loss. This may indicate that the demineralized dentin layer was not able to resist to the erosive cycling, possibly due to the intensity of the chosen cycling (11). Another possibility would be the degradation of the organic matrix by MMPs in dentin and saliva (22), activated by the fall and
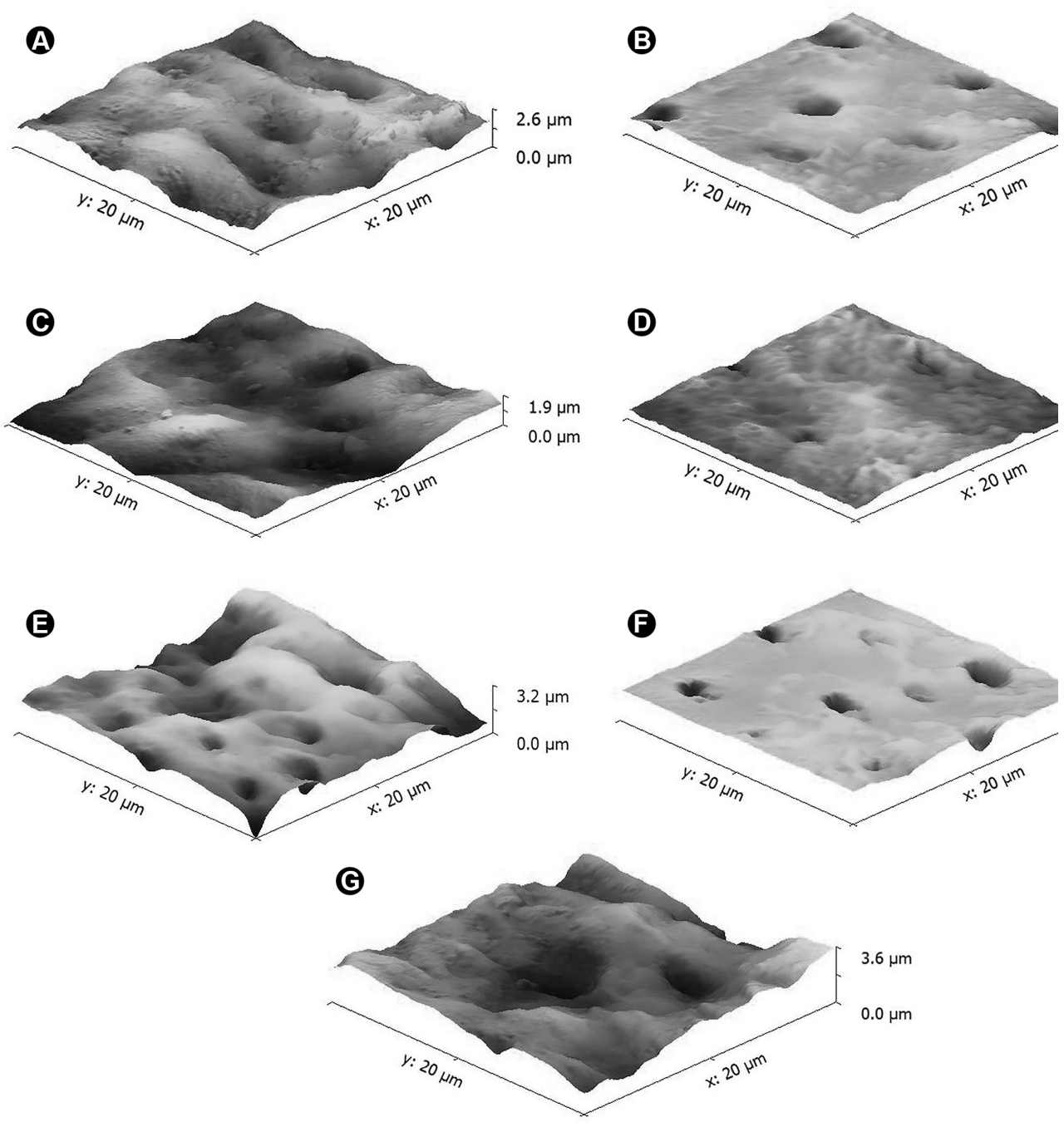

Figure 5. Photomicrographs obtained in AFM of $\mathrm{C} 1$ (A), $\mathrm{TiF}_{4} 1$ (B), C2 (C), $\mathrm{TiF}_{4} 2(\mathrm{D}), \mathrm{C} 3(\mathrm{E}), \mathrm{TiF}_{4} 3(\mathrm{~F})$ and $\mathrm{UN}(\mathrm{G})$ groups after the in situ stage. 
subsequent pH neutralization of the oral environment (22). Regardless the reason, with the removal of the protection conferred by collagen fibres, the partially demineralized layer beneath it is exposed and becomes susceptible to the action of acids, giving rise to the progression of mineral loss (1).

This uncertainty on the maintenance of organic matrix after erosive/abrasive cycling performance may be considered a limitation of the present study, since the method chosen to evaluate surface loss is sensitive to the presence of any artifact on the measuring area. However, optical profilometry allows the performance of multiple scans on the same sample, which made possible evaluations after erosive-like lesions formation and at the in situ phase. Considering that results may be influenced by matrix shrinkage/compression - caused by dentin dehydration and abrasive procedure -, in order to minimize possible bias, there was a thorough moisture control during analysis (12) and standardization of intraoral abrasion (11).

Another limitation of the present study might be the absence of a positive control group. Recent literature presents unsatisfactory results for $\mathrm{NaF}$ when tested as an agent for erosion control (3). Carboximetilcellulose placebo $\dot{s}$ gels have been also tested and presented little protection as well (23). Nowadays, the gold-standard treatment for erosive lesions might be the Elmex Erosion (24); however, as it is a solution with daily use recommendation, the comparison between results obtained would not be possible. Based on that, authors of the present study decided to compare $\mathrm{TiF}_{4}$ effects only with untreated samples, since the inclusion of additional groups on the in situ phase would make it longer and demand extra cooperation from volunteers. Anyway, considering the positive results presented by $\mathrm{TiF}_{4}$ applications, this fluoride may represent an alternative for in-office treatment for erosion and further studies aiming to develop more stable formulations, which could be stored for longer periods, are strongly advised. After that, clinical trials could confirm the results and provide the professionals the necessary support for safe clinical use.

Despite the potential effect of $\mathrm{TiF}_{4}$, there is still the need for patient education on the modification of harmful eating habits (25) and other attitudes able to accelerate the progression of erosive lesions (25). Therefore, in spite of the protection provided by the fluoride applied, the lesion progression may be delayed, but not inhibited. Under this assumption, the action of $\mathrm{TiF}_{4}$ could present even more promising results if the erosive challenges have ceased, since the presence of acid did not inhibit the formation of the glaze. Clinically, with a reduction of risk factors (25), a re-precipitation of the mineral on the surface could be possible and the loss of dental substrate could be interrupted. However, in the absence of modification of the patient habits, there may be the need of new $\mathrm{TiF}_{4}$ applications so its action is prolonged and may prevent the continuation of the erosive process.

Within the limitations of this study, 4\% gel $\mathrm{TiF}_{4}$ was able to reduce the progression of erosive/abrasive lesions in dentin in thefirst application and multiple applications reduced the evolution of the erosive process.

\section{Resumo}

A incidência da erosão tem aumentado e o seu controle ainda é um desafio na prática clínica. Este estudo avaliou os efeitos do gel de $\mathrm{TiF}_{4}$ a $4 \%$ sobre a dentina humana erodida submetida a episódios erosivos/abrasivos in situ. Setenta e dois fragmentos de dentina previamente erodida (ácido citrico $0,05 \mathrm{M}, \mathrm{pH} 2,3,20 \mathrm{~min}$ ) foram distribuidas em 6 grupos ( $n=12$ ) de acordo com o tratamento a ser realizado durante a fase in situ e o número de ciclos erosivos/abrasivos, como descrito a seguir: gel de $\mathrm{TiF}_{4}$ a $4 \%$ aplicado uma $\left(\mathrm{TiF}_{4} 1\right)$, duas $\left(\mathrm{TiF}_{4} 2\right)$ ou três vezes $\left(\mathrm{TiF}_{4} 3\right)$ seguido de 1,2 e 3 ciclos erosivos/abrasivos, respectivamente. As aplicações dos géis foram realizadas antes do início do ciclo erosivo seguinte. Grupos controle foram submetidos a 1 (C1), 2 (C2) e 3 (C3) ciclos erosivos/abrasivos apenas. Um sétimo grupo $(\mathrm{n}=12)$ compreendia amostras sem erosão in vitro (UN) submetidas a 3 ciclos erosivos/abrasivos. Cada ciclo correspondia a 2 dias de desafios erosivos (ácido cítrico a 0,5\%, pH 2,6,6x/dia) e abrasivos (escova de dentes elétrica, 10 s/amostra, 1x/dia). As amostras foram avaliadas em perfilômetro e Microscopia Eletrônica de Varredura Ambiental (MEV). Imagens de microscopia de força atômica (AFM) também foram capturadas $(n=3)$. ANOVA a 2-fatores para medidas repetidas e o teste de Tukey $(p<0,001)$ demonstraram que $\mathrm{TiF}_{4} 2$, que não diferiu do $\mathrm{TiF}_{4} 1 \mathrm{e} \mathrm{TiF}_{4} 3$, revelou redução significativa na perda de superfície quando comparado a todos os grupos controle. $\mathrm{TiF}_{4} 1$ e $\mathrm{TiF}_{4} 3$ não apresentaram diferença estatisticamente significativa em relação ao $\mathrm{C} 1$, mas ambos os grupos demonstraram perda de superficie significativamente menor que C2 e C3. Micrografias de MEV e AFM sugeriram alterações nas superfícies tratadas quando comparadas a amostras dos grupos controle, apresentando redução no diâmetro das luzes dos túbulos dentinários. Portanto, o $\mathrm{TiF}_{4}$ foi capaz de reduzir a progressão das lesões erosivas/abrasivas.

\section{Acknowledgements}

The authors would like to thank the financial support given by CAPES, FAPESP (Fundação de Amparo à Pesquisa do Estado de São Paulo) and CNPq (Conselho Nacional de Desenvolvimento Científico e Tecnológico). The funders had no role in study design, data collection and analysis, decision to publish, or preparation of the manuscript. We also thank CNPEM for the technical assistance with the Atomic Force Microscopies.

\section{References}

1. Lussi A, Schlueter N, Rakhmatullina E, Ganss C. Dental erosion - an overview with emphasis on chemical and histopathological aspects. Caries Res 2011;45:2-12.

2. Vieira A, Ruben JL, Huysmans MCDNJM. Effect of titanium tetrafluoride, amine fluoride and fluoride varnish on enamel erosion in vitro. Caries Res 2005;39:371-379.

3. Magalhães AC, Dos Santos MG, Comar LP, Buzalaf MA, Ganss C, Schlueter N. Effect of a single application of TiF4 varnish versus daily use of a low-concentrated TiF4/NaF solution on tooth erosion prevention in vitro. Caries Res 2016;50:462-470.

4. Wahengbam $P$, Tikku AP, Lee WB. Role of titanium tetrafluoride (TiF4) in conservative dentistry: A systematic review. J Conserv Dent $2011 ; 14: 98-102$.

5. Wiegand A, Magalhães AC, Attin T. Is titanium tetrafluoride (TiF4) effective to prevent carious and erosive lesions? A review of the literature. Oral Health Prev Dent 2010;8:159-164. 
6. Basting RT, Leme AA, Bridi EC, Amaral FL, França FM, Turssi $\mathrm{CP}$,et al.. Nanomechanical properties, SEM and EDS microanalysis of dentin treated with 2.5\% titanium tetrafluoride, before and after an erosive challenge. J Biomed Mater B Appl Biomater 2015;103:783-789.

7. Tveit $A B$, Klinge $B$, Tötdal $B$, Selvig KA. Long-term retention of TiF4 and SnF2 after topical application to dentin in dogs. Scand J Dent Res 1988;96:536-540.

8. Mundorff SA, Little MF, Bibby BG. Enamel dissolution: II. Action of titanium tetrafluoride. J Dent Res 1972;51:1567-1571.

9. Wiegand A, Magalhães AC, Sener B, Waldheim E, Attin T. TiF4 and NaF at $\mathrm{pH} 1.2$ but not at $\mathrm{pH} 3.5$ are able to reduce dentin erosion. Arch Oral Biol 2009;54:790-795.

10. Ganss C, Lussi A, Sommer N, Klimek J, Schlueter N. Efficacy of fluoride compounds and stannous chloride as erosion inhibitors in dentine. Caries Res 2010:44:248-252.

11. Schlueter N, Klimek J, Ganss C. Effect of a chitosan additive to a Sn2+containing toothpaste on its anti-erosive/anti-abrasive efficacy - a controlled randomized in situ trial. Clin Oral Invest 2014;18:107-115.

12. Magalhães $A C$, Levy $F M$, Rios $D$, Buzalaf MAR. Effect of a single application of TiF4 and $\mathrm{NaF}$ varnishes and solutions on dentin erosion in vitro. J Dent 2010;38:153-157.

13. Keskin B, Aktas A. Statistical power analysis. The 7th International Days of Statistics and Economics, 2013;578-587.

14. Lussi A, von Salis-Marincek M, Ganss C, Hellwig E, Cheaib Z, Jaeggi, T. Clinical study monitoring the $\mathrm{pH}$ on tooth surfaces in patients with and without erosion. Caries Res 2012;46:507-512.

15. Moazzez RV, Austin RS, Rojas-Serrano M, Carpenter G, Cotroneo E, Proctor $\mathrm{G}$ et al. Comparison of the possible protective effect of the salivary pellicle of individuals with and without erosion. Caries Res 2014;48:57-62.

16. Borges AB, Scaramucci T, Lippert F, Zero DT, Hara AT. Erosion protection by calcium lactate/sodium fluoride rinses under different salivary flows in vitro. Caries Res 2014;48:193-199.

17. Ganss C, Lussi $A$, Scharmann I, Hardt M, Klimek J, Schlueter N Comparison of calcium analysis, longitudinal microradiography and profilometry for the quantitative assessment of erosion in dentine. Caries Res 2009;43:422-429.

18. Büyükyilmaz $\mathrm{T}, \mathrm{Ogaard} B$, Rolla $\mathrm{G}$. The resistance of titanium tetrafluoride-treated human enamel to strong hydrochloric acid. Eur J Oral Sci 1997;105:473-477.

19. Sen BH, Kazemi RB, Spangberg LSW. Morphologic effects on L929 fibroblasts of titanium tetrafluoride application. Oral Surg Oral Med Oral Pathol Oral Radiol Endod. 1998;86:341-346.

20. Shresta BM. Effect of systemic titanium fluoride (TiF4) on fluoride uptake by developing rat enamel. Caries Res 1983;17:264-266.

21. Hara AT, Ando M, Cury JA, Serra MC, González-Cabezas C, Zero DT. Influence of the organic matrix on root dentine erosion by citric acid. Caries Res 2005;39:134-138.

22. Tjäderhane L, Larjava $H$, Uitto VJ, Larmas $M$, Salo T. The activation and function of host matrix metalloproteinases in dentin matrix breakdown in caries lesions. J Dent Res 1998;77:1622-1629.

23. Barbour ME, Shellis RP, Parker DM, Allen GC, Addy M. An investigation of some food-approved polymers as agents to inhibit hydroxyapatite dissolution. Eur J Oral Sci 2005;113:457-461.

24. Rakhmatullina $E$, Beyeler B, Lussi A. Inhibition of enamel erosion by stannous and fluoride containing rinsing solutions. Schweiz Monatsschr Zahnmed 2013;123:192-198.

25. Zero DT. Etiology of dental erosion - extrinsic factors. Eur J Oral Sci 1996;104:162-177.

Received August 16, 2016 Accepted March 14, 2017 